\title{
Patient's expectation of orthodontic treatment attending tertiary care dental hospital in Kathmandu
}

\author{
Dr. Bikash Veer Shrestha', Dr. Anshu Piya², Dr. Anju Khapung ${ }^{3}$, Dr. Prakash Bhattarai ${ }^{4}$ \\ ${ }^{1}$ Assistant Professor, ${ }^{2}$ Associate Professor, ${ }^{4}$ Professor, \\ Department of Orthodontics and Dentofacial Orthopaedics, Nepal Medical College and Teaching Hospital \\ ${ }^{3}$ Lecturer, \\ Department of Community and Public Health Dentistry, Nepal Medical College and Teaching Hospital \\ Corresponding author: Dr. Bikash Veer Shrestha; Email: becash2002@yahoo.com
}

\section{ABSTRACT}

Introduction: Understanding of patient's expectation and attitude towards orthodontic treatment plays an important role towards a successful treatment outcome and behavioral management.

Materials and Method: All the patients (270) attending department of Orthodontics in Nepal Medical College for the first time were included in the study. The descriptive study is done. A structured questionnaire was used to obtain the socio-demographic information and responses to questions on their expectation of orthodontic treatment.

Results: Majority of the respondents had higher expectations on aesthetic outcome of orthodontic treatment than the functional outcomes. They expected to have better smile, teeth straightened and have confidence socially. The lowest mean scores were obtained in the domains of improvement in career and making speech easier. Females had significant higher scores than male participants in all domains explored with the mean highest score in the domain of better smiles; while the highest male mean score was in the domain of straightened teeth.

Conclusion: To achieve successful orthodontic treatment result, patient cooperation is necessary. Agreeing with the patient on realistic expected treatment outcomes by the orthodontist before the treatment is required so that they are not disappointed with the final appearance.

KEYWORDS: Orthodontic treatment, Malocclusion, Patient expectation

\section{INTRODUCTION}

Patient has specific expectations during their visit to health care providers, which usually reflects concerns and problems they want the health service providers to address during their consultation. They have a specific agenda when visiting the health service providers, which usually reflects concerns and problems they want the health service providers to address during consultation. ${ }^{1}$ The main objective of health care system is to fulfill patient's expectations and the clinician who is aware of a patient's expectations is better able to satisfy the patient's justified desires and to initiate discussions about those expectations that are unrealistic, leading to more productive clinical negotiations. ${ }^{2}$

Usually expectation of patients towards orthodontic treatment depends on the perception of their own dentofacial esthetics and on the continuous feedback or pressure they receive from their peers. Therefore, their decision to search for orthodontic treatment is motivated by social norms and culture in their society and the reference group. ${ }^{3}$ People these days being more concerned about their esthetics and well being, there will be inevitably increase in demand for orthodontic treatment and a greater awareness amongst the patients and better results from orthodontic treatment will also be expected. ${ }^{4}$ Improvements in social life and self-confidence are additional potential benefits as seen by patients. ${ }^{5}$

Orthodontics is the field of dentistry concerned with the supervision, guidance and correction of the growing dentofacial structures applying various forces and/ or the stimulation and redirection of the functional 
forces within the craniofacial complex. ${ }^{3}$ Orthodontic treatment also has a significant impact on psychosocial aspect of the patients. It has been estimated that about $80 \%$ of orthodontic patients seek treatment out of aesthetic concern rather than the health and function. ${ }^{6,7}$ Understanding patients' expectations of treatment can help detail the parameters for informed consent as well as help patients develop coping methods to deal with treatment sequelae. ${ }^{4}$

Li W, Wang $S$ and Zhang $Y^{8}$ performed a study to examine treatment motivation and expectation associated with treatment-outcome satisfaction in a group of adolescent nonextraction orthodontic patients. Before treatment, questionnaire 1 was given to patients to assess treatment motivation and expectations and when treatment had been completed, questionnaire 2, concerning treatment satisfaction, was assessed. It was found that motivation was correlated with satisfaction with treatment outcome but patients' expectations had no correlation with treatment satisfaction. ${ }^{8}$

Although various studies have been performed regarding patient expectations during the first dental visit, there is a lack of research evidence in Nepalese population. Greater understanding of patients' expectations of the orthodontic treatment process and how it affects their day-to-day living or quality of life is important in many ways.

\section{MATERIAL AND METHODS}

A structured interviewer-administered questionnaire was used for data collection. The first part of the questionnaire obtained information on socio-demographic items including gender, age, level of education, as well as dental history. The second part obtained data on patients' expectations of orthodontic treatment and the questionnaire was adopted. ${ }^{6} \mathrm{~A}$ visual analogue scale (VAS) marked at $10 \mathrm{~mm}$ intervals was used as the Likert response format for all questions except questions assessing the expected duration of orthdodontic treatment and the frequency of follow up visits. Maximum score of 10 indicated a high expectation and score of 1 a low expectation. Convenient sampling technique was used to collect data from the available samples.

All the patients (270) aged 15-30 years who visited the Department of Orthdontics and Dentofacial Orthopedics, College of Dental Sciences and Hospital (CODSH), Nepal Medical College (NMC) was included in the study.

Sample size was calculated by using the formula for finite population size,

$$
\begin{aligned}
n & =\frac{\left(Z^{2} p q\right)}{d^{2}+\left(Z^{2} p q\right) / N} \\
& =74.5(\text { approx. } 75)
\end{aligned}
$$

Where, $Z=1.96, p=$ expected prevalence $=7.7 \%$ (proportion of respondents who expected to attend once monthly for follow up in a study by Afolabi 0 et al. ${ }^{6} q=1-p, d=$ margin of error $=0.05, \mathrm{~N}=$ Finite population (Total number of new dental patients visiting orthodontic department in last 6 months as obtained from dental OPD register) $=210$

Equal number of male and female patients was included in the study. Patients with age range of 15-30 years and attending Department of Orthodontics and Dentofacial Orthopedics for the first time were included in the study. ${ }^{6}$

Mentally handicapped, psychologically ill, patients with craniofacial syndromes or anomalies along and patients who refused to give informed consent were excluded.

Data was entered in Microsoft Excel and exported to Statistical Package for Social Sciences version 16 for statistical analysis. Descriptive statistics were presented in the form of frequency distribution tables and measures of central tendency and dispersion were also computed for numerical variables. Independent $t$ test was used to assess the difference in mean VAS scores between male and female regarding expectations at their initial appointment and expectations on outcome of orthodontic treatment. Chi square test was used to find the association of gender with frequency/ duration of orthodontic treatment. P-value $<0.05$ was considered to be statistically significant.

Ethical clearance (Ref. No. 022-078/079) was taken from Institutional Review Committee (NMC-IRC), Nepal Medical College.

\section{RESULTS}

A total of 270 study participants were included in the study of which 140 (51.9\%) were male and 130 (48.1\%) were female. The age of the study participants ranged from 15 to 35 years.

Regarding the expectations of the study participants at their initial orthodontic appointment (Table 1), the study participants had higher expectations in the domains: have a discussion about treatment (9.48), perception about orthodontic treatment giving problem/ pain (8.86) and have oral hygiene checked (8.75). The least expected procedures were braces, don't know what type (3.80), jaw surgery (3.70) and train track braces (1.00), these domains having lower mean VAS scores. There was a statistically significant difference in mean VAS scores in the domains: have braces fitted (P-value 0.01), have a discussion about treatment (P-value 0.03$)$, have $x$-rays (P-value 0.03 ) and perception about orthodontic treatment giving problem/ pain $(P$-value $<0.001)$ and female had higher mean VAS scores than male in these domains. 
Table 2: There is significant association of elastomeric separators with pain perception and pain affecting life at 4th hour, 24th hour. Significant Association of Medication with the post separator placement pain also is significant at 4th and 24th hour of post separator placement.

\begin{tabular}{|c|c|c|c|c|}
\hline \multirow[b]{2}{*}{ Expectations at initial appointment } & \multicolumn{3}{|c|}{ Mean VAS score } & \multirow[b]{2}{*}{ P-value } \\
\hline & \begin{tabular}{|l} 
Male \\
mean $\pm S D$
\end{tabular} & $\begin{array}{l}\text { Female } \\
\text { mean } \pm S D\end{array}$ & $\begin{array}{l}\text { Total } \\
\text { mean } \pm S D\end{array}$ & \\
\hline Have braces fitted & $6.49 \pm 3.75$ & $7.62 \pm 3.38$ & $7.04 \pm 3.61$ & $0.01 *$ \\
\hline Have check-up and diagnosis & $8.37 \pm 3.25$ & $7.88 \pm 3.79$ & $8.13 \pm 3.52$ & 0.25 \\
\hline Have a discussion about treatment & $9.31 \pm 1.51$ & $9.66 \pm 1.12$ & $9.48 \pm 1.35$ & $0.03^{*}$ \\
\hline Have x-rays & $4.34 \pm 4.36$ & $5.50 \pm 4.52$ & $4.90 \pm 4.47$ & $0.03^{*}$ \\
\hline Have impressions & $5.89 \pm 4.50$ & $5.98 \pm 4.49$ & $5.93 \pm 4.49$ & 0.86 \\
\hline Have oral hygiene checked & $8.99 \pm 2.54$ & $8.49 \pm 3.09$ & $8.75 \pm 2.82$ & 0.16 \\
\hline Type of orthodontic treatment expected & $4.98 \pm 3.67$ & $4.63 \pm 3.88$ & $4.81 \pm 3.77$ & 0.45 \\
\hline Braces, don't know what type & $3.82 \pm 3.80$ & $3.77 \pm 3.96$ & $3.80 \pm 3.87$ & 0.91 \\
\hline Train track braces & $1.00 \pm 0.00$ & $1.00 \pm 0.00$ & $1.00 \pm 0.00$ & NA \\
\hline Teeth extracted & $6.44 \pm 4.14$ & $5.45 \pm 4.25$ & $5.96 \pm 4.21$ & 0.05 \\
\hline Jaw surgery & $3.80 \pm 4.05$ & $3.60 \pm 3.64$ & $3.70 \pm 3.85$ & 0.67 \\
\hline Perception about orthodontic treatment giving problem/ pain & $8.49 \pm 1.95$ & $9.26 \pm 1.56$ & $8.86 \pm 1.81$ & $<0.001^{*}$ \\
\hline Opinion about wearing braces giving problems & $8.66 \pm 1.89$ & $8.55 \pm 1.93$ & $8.61 \pm 1.91$ & 0.66 \\
\hline Problem with orthodontic treatment when eating & $8.81 \pm 2.52$ & $8.52 \pm 3.07$ & $8.67 \pm 2.79$ & 0.41 \\
\hline Orthodontic treatment to restrict what you can eat or drink & $7.91 \pm 3.11$ & $7.88 \pm 3.41$ & $7.89 \pm 3.26$ & 0.94 \\
\hline Opinion about how people will react to wearing brace & $8.19 \pm 2.42$ & $7.74 \pm 2.91$ & $7.97 \pm 2.67$ & 0.17 \\
\hline
\end{tabular}

VAS: Visual analogue scale, SD: standard deviation, NA: not applicable, $P$-value $<0.05$ statistically significant*

Regarding the expectations of the study participants on outcome of orthodontic appointment (Table 2), all the study participants had high expectations to have their teeth straightened (10), have a better smile (10), making easier to keep teeth clean (10) and have confidence socially (10). There was no statistically significant difference in mean VAS scores regarding outcome of orthodontic treatment in the domains of making easier to eat (P-value 0.96 ) and improving chance of good career (P-value 0.44$)$.

Table 3: Expectations of study participants on duration/ frequency of orthodontic treatment

\begin{tabular}{|l|l|l|l|l|l|}
\hline \multicolumn{2}{|l|}{ Expectations } & Male $\mathbf{n}(\%)$ & Female $\mathbf{n}(\%)$ & Total $\mathbf{n}(\%)$ & P-value \\
\hline \multirow{2}{*}{ Duration of treatment } & 1.5 years & $18(12.8)$ & $35(26.9)$ & $53(19.6)$ & \multirow{2}{*}{$<0.001^{*}$} \\
\cline { 2 - 5 } & 2 years & $81(57.9)$ & $83(63.9)$ & $164(60.8)$ & \\
\cline { 2 - 5 } & $>2$ years & $41(29.3)$ & $12(9.2)$ & $53(19.6)$ & \\
\hline Frequency of treatment & $>$ once monthly & $41(29.3)$ & $17(13.1)$ & $58(21.5 \%)$ & \multirow{2}{*}{$0.001^{*}$} \\
\cline { 2 - 5 } & Once monthly & $99(70.7)$ & $113(86.9)$ & $212(78.5)$ & \\
\hline
\end{tabular}




\section{DISCUSSION}

The objective of this study was to understand the expectations of orthodontic patient so as to provide them quality treatment with satisfaction of the treatment outcome.

The result of this study is in agreement with the study done by Soni et $\mathrm{al}^{5}$ in 2016 to evaluate patient's expectations of orthodontic treatment at first visit in 10 to 25 years in Indian population. From the study it was found that Indian patients had higher expectations of check-up and diagnosis or discussion about treatment at their initial visit. They expected more orthodontic fixed appliances, straight teeth, better smile and its effects on speech and mastication. They also expected that wearing braces would be painful and there would be more dietary and drinking restrictions. Significant differences between males and females were found for pain, dietary and drinking restrictions, career improvement, treatment time and type of orthodontic treatment.

Similar result was found in the study done by Rasool et al ${ }^{2}$ among 50 physically and mentally healthy participants in the age range of 15 to 30 years. The patients were well aware of every aspect of the orthodontic treatment and their expectations could be easily met leading to more patient satisfaction.

A study was performed to know the patients expectation of orthodontic treatment among 140 participants. 70 patients aged 12-14 years and one parent of each patient was also included in the study. A valid and reliable measure of orthodontic expectations in participants aged 12-14 years and their parents were provided by this study. A very good level of expectation among two responses were achieved. ${ }^{9}$ Similarly higher level of orthodontic treatment result expectation was desired by the participants in this study.

For successful outcome to achieve, a better understanding of the expectation for orthodontic treatment and the relationship of the orthodontist and patients are necessary. A study was performed to determine patients expectations from orthodontic treatment and from this study it was concluded that the patient expectation influenced the factors like patient satisfaction, patient cooperation, treatment outcome, and compliance. ${ }^{3}$ For those reasons better understanding of patients expectation for orthodontic treatment is of prime importance.

Dental appearance and function improvement related to the treatment benefits were most expected in this study by the participants. ${ }^{7}$
Most subjects in our sample expected an improvement in appearance as the outcome of orthodontic treatment similar to few other studies performed. ${ }^{10-11}$

Before starting the treatment, orthodontists should always ask their patients what they expect from the orthodontic treatment. Knowing and meeting their demands may lead to more satisfaction and less disappointment. ${ }^{11}$

In this study the participants had higher expectation to have check-up, diagnosis and interview about treatment done at the initial visit. They thought that the orthodontic treatment proved to improve their smile, made it easier to eat and made them confident socially. ${ }^{12}$

It was found that all new orthodontic patients irrespective of their perception mentioned, they expected that wearing orthodontic braces would be difficult. ${ }^{13}$

According to Awaisi ZH et al. ${ }^{14}$ majority of the patients were concerned about their self being and felt that orthodontic treatment would improve their dento-facial concerns, which is in agreement with our study.

Present study contradicts with the result of one of the study done in London. In that study the expectations of patients differed from those of their parents with regard to dietary and drink restrictions in relation to orthodontic treatment. ${ }^{15}$

Dental appearance and function improvement were most expected in studies relate to the treatment benefits. ${ }^{16-18}$

A study was done in Nigerian population in 2016 to study the patients' exception of orthodontic treatment. They expected to have better smile, straight teeth and have confidence socially. The lowest mean scores were obtained in the domains of improvement in career and improvement of speech. Female predisposition was higher.6 Which supports the result of the present study. Some studies have observed that females are more critical and anxious about their appearance than males. ${ }^{19-21}$

Functional aspects of malocclusion such as inability to chew were not significantly associated with the desire for orthodontic treatment ${ }^{22}$ while the present study contradicts with the result. The participants had higher demand of function improvement.

\section{CONCLUSION}

Majority of the respondents in this study did know the duration of orthodontic treatment and the frequency of 
their review appointments. Their aesthetic expectation of outcome of orthodontic treatment was higher than the functional outcomes. The duration of treatment, which includes the period of retention, may affect the compliance of the patient if he/she is not adequately prepared. It is thus necessary to inform the patient regarding adequate information on these critical aspects of their treatment. It is also recommended that the orthodontist agree with the patients on realistic expected treatment outcomes before the treatment commences so that they are not disappointed with the final appearance.

\section{Rationale of the study}

Orthodontic treatment relies mostly on patient cooperation for a successful end result. It is recommended for the orthodontist to agree with the patient on realistic expected treatment outcomes before the treatment starts so that they are not disappointed with the final appearance. The successful outcome of orthodontic treatment requires not only knowledge and technical competence of the treating orthodontist but also considerable effort on the part of the patient. By understanding expections of patients on the treatment outcome will enable the orthodontists on successful treatment plan and help to achieve satisfaction of patients.

\section{REFERENCES}

1. Berhane A and Enquselassie F. Patient expectations and their satisfaction in the context of public hospitals. Patient Pref Adherence 2016;10: 1919-28

2. Rasool G, Nausheen A, Hassan N, Bashir S and Raza H A. Orthodontic treatment and patient's expectations. POJ. $2012: 4(2)$ 44-7.

3. Gupta M and Barretto ES. Patient's Expectations from Orthodontic Treatment. Int J Prev Clin Dent Res. July-September $2017 ; 4(3): 238-40$.

4. Chen M, Wang D Wand Wu LP. Fixed Orthodontic Appliance Therapy and Its Impact on Oral Health-Related Quality of Life in Chinese Patients. Angle Orthod. 2010; 80 (1): 49-53.

5. Soni U N, Dash S, Baheti M, Baldawa R and Toshniwal N G. Patient's expectations of orthodontic treatment at first visit. IP indian J Orthod Dentofacial Res. April-June 2016; 2(2): 70-6.

6. Afolabi O, Ogunbiyi OB, Kikelomo AO and Olawande AA. Patient's Expectation of Orthodontic Treatment at a Tertiary Health Facility in Lagos, Nigeria. OJN. 2016; 6(1); 12-7.

7. Yao J, Li DD, Yang YQ, Mc Grath JCP and Mattheos N. What are patients' expectations of orthodontic treatment: A Systematic Review, BMC Oral Health. 2016; 1-40.

8. Li W, Wang S and Zhang Y. Relationships among satisfaction, treatment motivation, and expectations in orthodontic patients: a prospective cohort study. Patient Pref Adherence. 2016; 10: 443-7

9. Sayers MS AND Newton JT. Patients' Expectations of Orthodontic Treatment: Part 1 - Development of a Questionnaire. J Orthod. 2006; 33(4): 258-69.

10. Tung AW, Kiyak AH. Psychological influences on the timing of orthodontic treatment. Am J Orthod Dentofacial Orthop 1998; 113: 29-39.

11. Duggal R and Bansal S. Expectations from orthodontic treatment patient / parent perspective. Journal of Clinical and Diagnostic Research. 2010;(4): 3648-53.

12. Guler OC and Malkoc S. Patients' Expectations from Orthodontic Treatment. Van Sag Bil Derg. 2020; 13(3): 15-9.

13. Shrestha R K. Assessment of patient's perception and reaction towards orthodontic treatment. SL Dent Oral Disord Ther. 2017; 1(1): 1-4.

14. Awaisi ZH, Asad S, Mahmood A. Patient perception regarding impact of Orthodontic treatment. Pakistan Oral \& Dental Journal 2011; $31(1): 96-9$.

15. Al-zarea BK. Satisfaction with Appearance and the Desired Treatment to Improve Aesthetics. Indian J Dermatol. $2013 ; 1$-8.

16. Sayer MS and Newton JT. Patients' expectations of orthodontic treatment: part 2--findings from a questionnaire survey. J Orthod. 2007; 34(1): 25-35

17. Yao J, Li D, Yang Y, Mc Grath CP and Mathheos N. What are patients' expectations of orthodontic treatment: a systematic review. BMC Oral Health; 2016.

18. Sayers MS, Cunningham SJ and Newton TJ. Patients' expectations: is there a typical patient? J. Orthod. 2020; 47(1): 38-46.

19. Marques LS, Ramos-Jorge ML, Paiva SM, Pordeus IA: Malocclusion: Aesthetic impact and quality of life among Brazilian schoolchildren. Am J Orthod Dentofacial Orthop. 2006; 129(3):424-7.

20. Kilpelainen PV, Phillips C, Tulloch JF: Anterior tooth position and motivation for early treatment. Angle Orthod. 1993, 63(3):171-4.

21. Vallittu PK, Vallittu AS, Lassila VP. Dental aesthetics: A survey of attitudes in different groups of patients. J Dent. 1996; 24:335-8.

22. Tuominen ML, Tuominen RJ. Factors associated with subjective need for orthodontic treatment among Finnish university applicants. Acta Odontol Scand. 1994; 52:106-10 